\title{
Role of High Dose Calcium in the Prevention of Preeclampsia
}

\author{
APARNA KHAN ${ }^{1}$, SUSIL KUMAR MANDAL ${ }^{2}$, AMITAVA PAL ${ }^{3}$
}

\begin{abstract}
:
Objectives: To assess the effect of supplementation of high dose of calcium(2gm) in prevention of preeclampsia.

Materials \& Methods: A randomized controlled clinical trial on 272 healthy nulliparous woman were randomly allocated into two groups by means of a computer generation randomization list. From 20 weeks of gestation until delivery who received $2 \mathrm{gm}$ of oral elemental calcium per day ( $n=127$ ) were assigned to high dose calcium group or the study group and 145 women were assigned to low dose calcium or control group, receiving $500 \mathrm{mg}$ of calcium per day. Ten women (3.67\%) were lost to follow up after randomization (4 in the study group and 6 in the control group). Thus a total of 123 woman in the study group and 139 in the control group were included in the final analysis. Data was collected by standard questionnaire, clinical examination and investigations and statistical analysis was performed by student's t-test, chi square tests. $P<0.05$ was statistically significant.
\end{abstract}

Results: Preeclampsia developed in Study Group were 5.7\% and Control Group 13.7\% and the difference was statistically significant (Chi-squares - 4.65, $d f=1, p=0.031$ ). There were $2.43 \%$ (3 of 123 women) preterm delivery in the study group and $7.91 \%$ (11 of 39 women) in the control group. So, there was a significantly lower risk of preterm delivery in the study group $(p=0.049)$. Intrauterine growth retardation (IUGR) was found in $3.25 \%$ and $9.35 \%$ of women in the study and the control groups respectively. The incidence is higher in the control group when compared to the study group $(p=0.045)$.

Conclusion: Calcium intake is beneficial for both pregnant women and her unborn child. Daily supplementation with 2 grams of calcium during pregnancy significantly reduced the risk of preeclampsia, preterm labor and IUGR. So, high dose calcium should be supplemented to all women during pregnancy in developing countries where preeclampsia and preeclampsia related morbidities and mortality are quite high.

Key Words: preeclampsia, high dose calcium

\section{Introduction:}

Preeclampsia, as defined by the Working Group of the National High Blood Pressure Education Program, is hypertension (blood pressure $>140 / 90 \mathrm{mmHg}$ using Korotkoff $\mathrm{V}$ sound for diastolic blood pressure) associated with proteinuria (300 mg or more in 24 hour urine $)^{1}$. Preeclampsia community guideline (PRECOG) takes only diastolic blood pressure of $\mathrm{e}^{\text {" }}$ $90 \mathrm{mmHg}$ to define hypertension ${ }^{2}$. Preeclampsia affects $7 \%$ of first pregnancies ${ }^{3}$ and responsible for $24 \%$ of all maternal deaths in India ${ }^{4}$.
The results of several clinical trials and meta-analyses have suggested that calcium supplementation reduces the incidence of preeclampsia ${ }^{5,6}$.

Low calcium intake may cause high blood pressure by stimulating either parathyroid hormone or rennin release, thereby increasing intracellular calcium in vascular smooth muscle ${ }^{7}$ leading to vasoconstriction. A possible mode of action for calcium supplementation is that it reduces parathyroid release and intracellular calcium and so decreases smooth muscle

1. Aparna Khan- MBBS, $\mathrm{MD}(\mathrm{G} \& \mathrm{O})$, Associate Professor,

2. Susil Kumar Mandal-MBBS, $M D(G \& O)$, Junior Resident

3. Amitava Pal-MBBS,DGO, MS(G \& O), DNB, Associate professor

Department of Obstetrics \& Gynaecology, Burdwan Medical College \& Hospital, Burdwan, West Bengal, India 
contractility, increases the production of vascular Nitric Oxide (NO) ${ }^{8}$ and prostacyclin. Calcium might also have an indirect effect on smooth muscle function by increasing magnesium levels ${ }^{9}$.

By reducing uterine smooth muscle contractility it prevents preterm labour ${ }^{10}$.

Prevention of Preeclampsia would be a great step forward in prenatal care. One such primary prevention is oral supplementation of high dose calcium( $2 \mathrm{gm} /$ day) after 20 weeks of pregnancy.

This study was undertaken to evaluate the effect of high dose $(2 \mathrm{gm})$ calcium in reducing incidence of preeclampsia in women at high risk of preeclampsia.

\section{Materials and Methods:}

A prospective randomized clinical trial on 272 healthy nulliparous women were randomly allocated into two groups by computer generation randomization table. From 20 weeks of gestation until delivery 127 were assigned to high dose calcium group or the study group who received $2 \mathrm{gm}$ of oral elemental calcium (4 tablets of $500 \mathrm{mg}$ each) per day and 145 women were assigned to low dose calcium or control groups , receiving $500 \mathrm{mg}$ of calcium(one active calcium tablet of $500 \mathrm{mg}$ and 3 placebo tablets of the same size, weight, and colours the calcium tablets) per day. Ten women (3.67\%) were lost to follow up after randomization (4 in the study group and 6 in the control group. Thus a total of 123 woman in the study group and 139 in the control group were included in the final analysis.

This study was conducted between May 2010 to April 2011, among the pregnant women attending Antenatal Clinic, Department of Obstetrics \& Gynecology BURDWAN MEDICAL COLLEGE AND HOSPITAL, BURDWAN, West Bengal, India. This institution serves as a tertiary care hospital catering people of West Bengal and adjoining state like Jharkhand. Nulliparous pregnant mothers (18-30 years) from poor socio- economic status having singleton gestation, Blood pressure (BP) lower than $140 / 90 \mathrm{mmHg}$ and no proteinuria detectable by a dipstick with first prenatal visit before 20 weeks of gestation were included in the study.

Each subject was informed regarding the details of the study and written consent was obtained from each of them before engaging in the trial. The women were examined every 4 weeks till 28 weeks of gestation then every 2 weeks till 36 weeks and weekly thereafter until delivery.

Initially detailed history regarding personal \& family history of hypertension were taken. Height, weight and Blood Pressure of all pregnant mothers were measured.

Apart from routine investigations like estimation of $\mathrm{Hb} \%$, Fasting and Post Prandial blood sugar, ABO grouping \& Rh typing, VDRL, HIV 1 \& 2 testing, Urine for protein, sugar, pus cells, epithelial cells etc. Stool for ova, parasite, cysts etc. anomaly scan at $20 \mathrm{wk}$, the following investigations were done

- Urinary albumin estimation by dipstick method.

- Serum and urinary calcium level.

- Serum urea, creatinine, uric acid estimation

- Liver function test.

- Bleeding time (BT), Clotting time (CT), and platelet count.

- Ophthalmoscopic examination for Retinal changes.

The following parameters were noted in the next all visits -

- BP

- Body weight

- $\mathrm{Hb} \%, \mathrm{BT}, \mathrm{CT}$, platelet count.

- Routine urine examination specially albumin.

- Serum and urinary calcium level.

- USG at 20 weeks, 32 weeks, 36 weeks

- Retinal changes.

- Serum uric acid.

- Liver function test.

- Any medical problems etc.

Plan for Analysis of Data :

Data were analyzed with SPSS 9 statistical software. Results were presented as mean $\pm \mathrm{SD}$, comparison between the groups were analyzed by unpaired student's t test. The Chi-square analysis was done where appropriate and $\mathrm{P}<0.05$ was considered as statistically significant

\section{Results:}

Table I showed $5.7 \%$ and $13.7 \%$ cases of preeclampsia developed in the study group and the control group respectively. This difference was statistically significant (Chi-squares $-4.65, \mathrm{df}=1, \mathrm{p}$ $=0.031$ ). 
Table II have shown a higher percentage of eclampsia in the control group (36.84\%) than the study group(28.57\%).

Table III depicts maternal and neonatal outcome in both the study and the control groups. There was a significantly lower risk of preterm delivery in the study group $(2.43 \%)$ in comparison to control group $(7.91 \%)$.
From Table 4 we have found that Mean Systolic Blood pressure (SBP, $\mathrm{mmHg}$ ) in study group was $130.03 \pm 10.68$ and in control group was $132.15 \pm 14.5(p<0.0001)$. Diastolic Blood Pressure (DBP, $\mathrm{mmHg}$ ) in study and control group were $81.44 \pm 8.65$ and $83.94 \pm 12.54$ respectively $(p=0.0009)$.

Table-I

Number of Preeclampsia detected in Study ( $n=123)$ and Control ( $n=139)$ Group

\begin{tabular}{lccccc}
\hline & Preeclampsia & Normal Pregnancy & Total & Percentage (\%) & p Value \\
\hline Study Group & 7 & 116 & 123 & 5.7 & $0.031^{\text {a }}$ \\
Control Group & 19 & 120 & 139 & 13.7 & \\
Total & 26 & 236 & 262 & 9.9 & \\
\hline
\end{tabular}

a significant value.

Table-II

Eclampsia detected among Pre eclamptic mothers both in study and Control Group

\begin{tabular}{lcc}
\hline & Study Groupn=7 & Control Groupn=19 \\
\hline Eclampsia & $2(28.57 \%)$ & $7(36.84 \%)$ \\
\hline
\end{tabular}

Table-III

Maternal and Neonatal outcome both in Study and Control Group.

\begin{tabular}{lccc}
\hline Variable & Study Group $(\mathrm{n}=123)$ & Control Group $(\mathrm{n}=139)$ & p value \\
\hline Preeclampsia & $7(5.7 \%)$ & $19(13.7 \%)$ & $0.03^{\mathrm{a}}$ \\
Preterm delivery & $3(2.43 \%)$ & $11(7.91 \%)$ & $0.04^{\mathrm{a}}$ \\
Gestational age at delivery(week) & $38.02 \pm 1.25$ & $38.08 \pm 1.26$ & $0.0042^{\mathrm{a}}$ \\
Birth weight(gm) & $2900 \pm 313.48$ & $2775 \pm 277.69$ & $0.038^{\mathrm{a}}$ \\
IUGR & $4(3.25 \%)$ & $13(9.35 \%)$ & $0.045^{\mathrm{a}}$ \\
Stillbirth & $3(2.43 \%)$ & $7(5.03 \%)$ & 0.27 \\
\hline
\end{tabular}

Values are given as mean \pm SD or number (percentage).

${ }^{\mathrm{a}}$ significant value.

Table -IV

Comparison of changes in blood pressure (BP) both in Study and Control Group

\begin{tabular}{lccc}
\hline Variable & Study group $(\mathrm{n}=123)$ & Control group $(\mathrm{n}=139)$ & $\mathrm{p}$ value \\
\hline Systolic BP, $\mathrm{mmHg}$ & $130.03 \pm 10.68$ & $132.15 \pm 14.55$ & $<0.0001^{\mathrm{b}}$ \\
Diastolic BP, $\mathrm{mmHg}$ & $81.44 \pm 8.65$ & $83.94 \pm 12.54$ & $0.0009^{\mathrm{b}}$ \\
\hline
\end{tabular}

Values are given as mean \pm SD (range).

bsignificant value. 


\section{Discussion:}

The randomized control trial shows that supplementation of $2 \mathrm{gm}$ calcium per day decreases the incidence of hypertensive disorders in pregnancy

Kumar $A$. et al. ${ }^{11}$ reported that the overall incidence of preeclampsia was $7.8 \%$ (41 of 524 women) and the incidence was $4.0 \%$ in the calcium group and $12.0 \%$ in the placebo group (OR, 0.31; 95\% Cl, 0.15-0.63). A $66.7 \%$ reduction in preeclampsia was observed in the calcium group.

The above report corroborated with our study (Chisquares - $4.65, \mathrm{df}=1, \mathrm{p}=0.031$, Table 1)and there was $58.39 \%$ reduction of preeclampsia in the present study which nearly corresponds to the study by Kumar A. et al.

Kumar A. et al. ${ }^{11}$ also reported that none of the women in either group (calcium and placebo group) developed eclampsia, but our study does not correlate well with their study because eclampsia detected in control and study group were $36.84 \%$ and $28.57 \%$ respectively (Table2)

In the present study, it was noted that $2.43 \%$ preterm delivery was in study group and $7.91 \%$ in control group $(p=0.04)$ and there is $69.27 \%$ reduction of preterm delivery (table-3) which is more significant than other study ${ }^{11}$.

The mean birth weight was significantly greater in the study group $(2900 \pm 313.48)$ than control group $(2775 \pm 277.69)(p=0.038)$. The incidence of IUGR was more higher in control group when compared to study group $(9.35 \%$ and $3.25 \%$ respectively) $(p=0.045)$. Stillbirths were also reduced in study group (2.43\%) than control group $(5.03 \%)$ $(p=0.27)$

Herrera JA et al. ${ }^{12}$ reported that mean birth weight was significantly greater in the calcium group ( $2979 \pm$ $448 \mathrm{~g})$ than placebo group ( $2705 \pm 433 \mathrm{~g})$, and the difference was statistically significant, $p<0.01$.

According to Niromanesh $S$ et al ${ }^{13}$ the infants born in the calcium supplemented group had on an average of $500 \mathrm{~g}$ or more weight at birth than infant from the placebo group (infant birth weight for calcium group was $3316 \pm 308 \mathrm{~g}$ and Placebo group was $2764 \pm 761$ $\mathrm{g}$, the difference was statistically significant $<0.05$ ).

So, our study also corroborated to the above two studies. The mean birth weight was significantly greater in the study group $(2900 \pm 313.48 \mathrm{~g})$ when compared to control group $(2775 \pm 277.69 \mathrm{~g})$, and $\mathrm{p}=$ 0.038 .

Herrera JA et al ${ }^{12}$ reported that mean maternal diastolic blood pressure at delivery was significantly higher in the placebo group $(p=0.005)$.

We found that Diastolic Blood Pressure (DBP, mmHg) in study and control group were $81.44 \pm 8.65$ and $83.94 \pm 12.54$ respectively $(p=0.0009)$ and both were almost similar.

So calcium supplementation in high dosage is very popular for reduction of incidence of preeclampsia and chances of renal stone formation is less as the duration of supplementation is short.

\section{Conclusion:}

In the light of our observation, calcium intake is beneficial for both pregnant women and their unborn child. Daily supplementation with 2 grams of calcium during pregnancy significantly reduced the risk of preeclampsia, preterm labor and IUGR. So, high dose calcium should be supplemented to all women during pregnancy in developing countries where preeclampsia and preeclampsia related morbidities and mortality are quite high.

\section{References:}

1. Working Group Report on High Blood Pressure in Pregnancy. National Institute of Health, National Heart, Lung and Blood Institute, National High Blood Pressure Education Program, NIH Publication No. 00-3029, Revised July 2000.

2. The preeclampsia community guideline (PRECOG): how to screen for and detect onset of preeclampsia in the community. BMJ 2005;330:576-580

3. WHO International Collaborative Study of Hypertensive Disorders of Pregnancy. Geographic variation in the incidence of hypertension in pregnancy. Am J Obstet Gynecol 1988; 158:80-83

4. Bedi N, Kamboj I, Dhillon BS, Saxena BN, Singh P. Maternal deaths in India - Preventable tragedies (An ICMR Task Force Study). J Obstet Gynaecol Ind 2001; 51:86-92

5. Levine RJ, Hauth JC, Curt LB, et al. Trial of calcium to prevent preeclampsia. N Engl J Med. 1997; 337: 69-76. 
6. Purwar M, Kulkarni H, Motghare V, et al. Calcium supplementation and prevention of pregnancy induced hypertension. J Obstet Gynecol Res. 1996; 22: 425-30.

7. Kawaski N, Matsuti K, Ito M, et al. Effect of calcium supplementation on the vascular sensitivity to angiotensin II in pregnant women. Am J Obstet Gynecol. 1985; 153: 576-82.

8. Lopez-Jaramillo P, Teran E, Moncada S. Calcium supplemention prevents pregnancy-induced hypertension by increasing the production of vascular nitric oxide. Med Hypotheses. 1995; 45: 68-72.

9. Repke JT, Villar J, Anderson C, Pareja G, Dubin $\mathrm{N}$, Belizan JM. Biochemical changes associated with blood pressure reduction induced by calcium supplementation during pregnancy. Am J Obstet Gynecol 1989; 160:684-90.
10. Villar J, Belizan JM, Repke J. The effect of calcium supplementation on the incidence of hypertensive disorders of pregnancy and prematurity $.7^{\text {th }}$ world Congress of Hypertension in Pregnancy; 1990; Perugia , Italy. 1990; 54.

11. Kumar A, Devi SG, Batra S, Singh C, Sukla DK, Calcium supplementation for the prevention of preeclampsia. Int J Obstet Gynecol 2009; 104:32-36.

12. Herrera JA, Shahabuddin AKM, Ersheng G, Wei Y, Gracia RG,Lopez-Jarmillo L. Calcium plus linoleic acid therapy for pregnancy induced hypertension Int J Obstet Gynecol 2005;91: 221-227

13. Niromanesh S, Laghaii S, Mossavi-Jarrahi A. Supplimentary calcium in prevention of preeclampsia Int J Obstet Gynecol 2001; 74:17-21. 